\title{
Nonalcoholic Fatty Liver Disease and Abdominal Fat Accumulation According to Vitamin D Status in Patients with Type 2 Diabetes (J Obes Metab Syndr 2018;27:53-60)
}

\author{
Bo-Yeon Kim*, Dug-Hyun Choi, Chan-Hee Jung, Ji-Oh Mok, Sung Koo Kang, Chul-Hee Kim \\ Division of Endocrinology and Metabolism, Department of Internal Medicine, Soonchunhyang University Bucheon \\ Hospital, Soonchunhyang University College of Medicine, Bucheon, Korea
}

Received May 31, 2018

Reviewed June 7, 2018

Accepted June 18, 2018

${ }^{*}$ Corresponding author

Bo-Yeon Kim

https://orcid.org/0000-0002-3658-2351

Division of Endocrinology and

Metabolism, Department of Internal

Medicine, Soonchunhyang University

Bucheon Hospital, Soonchunhyang

University College of Medicine, 170

Jomaru-ro, Wonmi-gu, Bucheon 14584, Korea

Tel: +82-32-621-5157

Fax: +82-32-621-5018

E-mail: byby815@schmc.ac.kr
The association between vitamin $\mathrm{D}$ level and nonalcoholic fatty liver disease (NAFLD) has not yet been established. However, several studies suggest that vitamin $\mathrm{D}$ deficiency is associated with NAFLD and obesity and abdominal obesity. ${ }^{1-3}$ Our study evaluated the association between NAFLD and abdominal fat accumulation according to vitamin $\mathrm{D}$ status in patients with type 2 diabetes. Ours is a clinic-based study showing that low vitamin $\mathrm{D}$ level is associated with NAFLD and abdominal visceral fat accumulation in Korean patients with type 2 diabetes, as reported in Journal of Obesity \& Metabolic Syndrome. ${ }^{4}$

As a reader mentioned, the association between vitamin $\mathrm{D}$ level and visceral adiposity/prevalence of NAFLD could be influenced by the different treatments, and the contradicting findings observed in this study might be affected by antidiabetic medications, antihypertensive medications, and other drugs. Insulin resistance is a very important contributor to the pathogenesis of NAFLD. Therefore, we plan to analyze the effect on abdominal fat accumulation of each antidiabetic medication in future study including these participants.
The other question was about the effect of vitamin $\mathrm{D}$ level on the prevalence of NAFLD independent of visceral fat thickness in the logistic regression model. When we analyzed further as the reader mentioned, vitamin $\mathrm{D}$ deficiency was associated with the prevalence of NAFLD after adjusting for visceral fat thickness in addition to the given logistic regression model. Because vitamin $\mathrm{D}$ is known to be involved in immune regulation and inflammatory responses, low vitamin $\mathrm{D}$ is thought to play a role in the pathogenesis of NAFLD by hepatic inflammation through adipocytokines. ${ }^{5}$ We thank you for your very important comment on this and plan to evaluate whether visceral adiposity is an important factor in the association of vitamin $\mathrm{D}$ status with NAFLD in the next study. Because of the lack of data, outdoor activity, dietary habits, and seasonal variations in vitamin $\mathrm{D}$ were also not included in our study. This is a limitation of our current study.

Lastly, our finding showed that the vitamin $\mathrm{D}$ deficiency group has increased visceral fat accumulation compared with the vitamin D sufficient group. However, in our study, body mass index

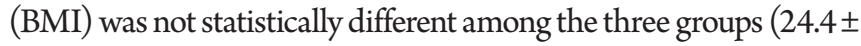


$4.0 \mathrm{~kg} / \mathrm{m}^{2}$ in the vitamin D deficient group, $24.8 \pm 4.2 \mathrm{~kg} / \mathrm{m}^{2}$ in the vitamin D insufficient group, and $25.2 \pm 3.8 \mathrm{~kg} / \mathrm{m}^{2}$ in the vitamin D sufficient group; $P=0.378$ ). Unlike our study, several previous studies showed an inverse association between vitamin D level and BMI. ${ }^{6,7}$ However, another Korean study showed that vitamin $\mathrm{D}$ level is not correlated with $\mathrm{BMI}$ in men and is negatively correlated with visceral fat in both sexes, similar to our study. ${ }^{8}$ These inconsistencies may be due to race, nutrition status, and BMI in the patients. Recent studies have reported that vitamin D may affect glucose metabolism and adipose tissue distribution. I agree with the reports, but I plan to obtain more information such as physical activity, sun exposure, and nutrition status of participants to explain why the vitamin $\mathrm{D}$ deficiency group had increased visceral fat accumulation compared with the vitamin D sufficient group. I agree that further, large prospective studies are required to elucidate the associations between vitamin D level and NAFLD and abdominal fat. Finally, we thank you for the letter and giving us an opportunity to respond it.

\section{CONFLICTS OF INTEREST}

The authors declare no conflict of interest.

\section{REFERENCES}

1. Angelico F, Del Ben M, Conti R, Francioso S, Feole K, Fiorello $\mathrm{S}$, et al. Insulin resistance, the metabolic syndrome, and nonalcoholic fatty liver disease. J Clin Endocrinol Metab 2005;
90:1578-82.

2. Bhatt SP, Misra A, Sharma M, Guleria R, Pandey RM, Luthra $\mathrm{K}$, et al. Vitamin D insufficiency is associated with abdominal obesity in urban Asian Indians without diabetes in north India. Diabetes Technol Ther 2014;16:392-7.

3. Hannemann A, Thuesen BH, Friedrich N, Völzke H, Steveling A, Ittermann $\mathrm{T}$, et al. Adiposity measures and vitamin $\mathrm{D}$ concentrations in northeast Germany and Denmark. Nutr Metab (Lond) 2015;12:24.

4. Choi DH, Jung CH, Mok JO, Kim CH, Kang SK, Kim BY. Nonalcoholic fatty liver disease and abdominal fat accumulation according to vitamin $\mathrm{D}$ status in patients with type 2 diabetes. J Obes Metab Syndr 2018;27:53-60.

5. Kwok RM, Torres DM, Harrison SA. Vitamin D and nonalcoholic fatty liver disease (NAFLD): is it more than just an association? Hepatology 2013;58:1166-74.

6. Drincic AT, Armas LA, Van Diest EE, Heaney RP. Volumetric dilution, rather than sequestration best explains the low vitamin D status of obesity. Obesity (Silver Spring) 2012;20:1444-8.

7. Young KA, Engelman CD, Langefeld CD, Hairston KG, Haffner SM, Bryer-Ash M, et al. Association of plasma vitamin D levels with adiposity in Hispanic and African Americans. J Clin Endocrinol Metab 2009;94:3306-13.

8. Park D, Kwon H, Oh SW, Joh HK, Hwang SS, Park JH, et al. Is vitamin $\mathrm{D}$ an independent risk factor of nonalcoholic fatty liver disease? A cross-sectional study of the healthy population. J Korean Med Sci 2017;32:95-101. 